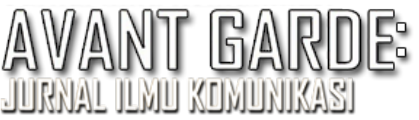

\title{
Humor Dan Satire Kartun Media Massa Sebagai Komunikasi Visual Di Era Disrupsi
}

\author{
Diana Suprayuni, Anik Juwariyah \\ e-mail: dianasuprayunii@gmail.com \\ Universitas Negeri Surabaya, Jl. Rektorat Unesa, Lidah Wetan, Kec. Lakarsantri, Surabaya
}

Submitted: 17 November 2019 Revised: 02 December 2019 Accepted: 19 December 2019

\begin{abstract}
Abstrak
Era disrupsi memberikan peluang dalam keunikan gaya penyampaian pesan persuasif melalui kartun yang menggambarkan opini dengan cara melebih-lebihkan dalam kartun media massa. Penelitian ini mencoba menganalisis bagaimana media massa merepresentasikan fenomena kekinian dengan media kartun. Penelitian ini juga ingin menunjukkan bahwa kartun dapat menjadi salah satu cara untuk mengamati sikap masyarakat terhadap sebuah fenomena melalui humor dan satire yang ada di dalamnya. Metode dalam penelitian ini adalah deskriptif kualitatif. Kajian penelitian ini dikelompokkan menjadi: 1) sasaran kajian terhadap perkembangan kartun dan media massa sebagai salah satu media komunikasi massa, 2) sasaran kajian satire dan humor yang ada dalam media komunikasi massa yang secara khusus dilihat dari sudut pandang kartun, dan 3) sasaran kajian yang didapatkan dari respon masyarakat terhadap kartun, humor, satire, dan komunikasi massa. Hasil penelitian menunjukkan bahwa kartun di era disrupsi dapat dimanfaatkan sebagai alternatif yang efektif untuk kritik dan memobilisasi dukungan untuk suatu tujuan. Kartun tidak hanya dimaksudkan sebagai humor, tetapi juga alat yang ampuh untuk mendorong perubahan. Humor dan satire dalam kartu dapat dikatakan mewakili praktik diskursif lucu yang dekat dengan sindiran yang telah menjadi lahan diskursif dalam media massa. Dengan asumsi bahwa humor dan satire dalam kartun merupakan bentuk pewacanaan dan bahkan pendidikan bagi masyarakat.
\end{abstract}

Kata kunci: era disrupsi, humor dan satire, kartun media massa, komunikasi visual

\section{Humor and Satire in Mass Media Cartoon as Visual Communication in the Disruption Era}

\begin{abstract}
The era of disruption provides opportunities in the unique style of delivering persuasive messages through cartoons that illustrate opinions by exaggerating them in mass media cartoons. This study tries to analyze how the mass media represent current phenomena with cartoon media. This research also wants to show that cartoons can be one way to observe people's attitudes towards a phenomenon through humor and satire in it. The method in this research is descriptive qualitative. This research study is grouped into: 1) the target of the study of the development of cartoons and mass media as one of the mass communication media, 2) the target of satire and humor studies in mass communication media specifically viewed from the perspective of cartoons, and 3) the target of the study which is obtained from the public response to cartoons, humor, satire, and mass communication. The results showed that cartoons in the era of disruption could be used as an effective alternative to criticism and mobilizing support for a goal. Cartoons are not only intended as humor, but also powerful tools to drive change. The humor and satire on the card can be said to represent humorous discursive practices that are close to satire which have become discursive land in the mass media. Assuming that humor and satire in cartoons are a form of discourse and even education for the community.
\end{abstract}

Keywords: disruption era, humor and satire, mass media cartoon, visual communication 


\section{PENDAHULUAN}

Perbedaan sedang dibuat tentang apa yang disebut sebagai era budaya dan artistik kontemporer, salah satunya dalam bidang komunikasi massa (Adesope \& Rud, 2019; Rossing, 2019). Studi yang dilakukan oleh David Schultz pada 2016 yang berjudul "Public Affairs Education for a New Generation" mengatakan bahwa paradigma komunikasi massa telah bergeser untuk memberikan ruang-ruang baru pada disiplin lain (Schultz, 2016), yang utamanya bertujuan untuk masuk ke dalamnya sebagai salah satu bentuk komunikasi baru (Darbellay \& Moody, 2017). Era kontemporer telah merambah disiplin media komunikasi dengan caranya sendiri, yaitu dengan mengaburkan batas-batas penyampaian klasikal. Istilah di sekitar kontemporer seperti remodernisme, performatisme, hypermodernisme, automodernisme, altermodernisme, digimodernisme, atau metamodernisme mulai muncul terkait gagasan tentang kondisi postmodern (Conway, 2015; Rossing, 2019). JeanFrançois Lyotard di La Condition Postmoderne: Rapport Sur Le Savoir (1979) menyatakan, era-era komunikasi sebelumnya masih dapat berfungsi sebagai langkah analitis tidak hanya untuk mempertimbangkan adegan kontemporer untuk seni sindiran, tetapi mungkin juga untuk mengevaluasi karyakarya satire yang diproduksi sebagai bentuk persuasif dalam komunikasi massa (Rowden, 2013). Komunikasi massa berkaitan erat dengan bidang seni, karena seni memiliki daya simbolis yang baik dalam hal persuasif kepada audiens (Daddesio, 2013; Liu \& Luton, 2011).
Salah satu bentuk yang memiliki unsur komunikasi, seni, persuasif, dan tepat untuk dikonsumsi massa adalah melalui media kartun. Kartun, yang merupakan gambar atau penggambaran sebuah pengaktualisasian objek konkret dengan cara melebih-lebihkan ciri khas objek tersebut (Gopnik, 2019; Haywood, 2019), yang mampu memberikan peluang terjadinya interpretasi dan makna baru (D’Angelo, 2010; Daddesio, 2013). Kartun di era saat ini memberikan kesempatan untuk terjadinya transfer pesan antara produsen dan konsumen secara non-verbal, sehingga dapat menjelaskan dan memberikan penekanan tertentu pada isi pesan sesuai dengan interpretasi konsumen secara simbolis. Kartun yang merupakan salah satu bentuk produk visual lebih mudah diingat dari pada kata-kata, serta yang paling cepat untuk pemahaman dan dimengerti, sehingga akan membuka peluang terjadinya kekerasan simbolis yang tidak disadari melalui kartun (Remley, 2017). Lebih lanjut, kartun dalam media baik online maupun offline. Kartun dalam media massa hadir tidak hanya sebagai media hiburan dan selingan, akan tetapi sebagai penyerbaran paradigma baru (Etty, 2019). Di Indonesia kartun dalam media massa bahkan menjadi ikon, seperti kartun Oom Pasikom dan Panji Koming, Ali Oncom, dan Karikatur Clekit. Karikatur itu sendiri adalah bagian kartun yang diberi muatan pesan bernuansa kritik atau usulan terhadap seseorang atau suatu masalah (Uidhir, 2013).

Kembali pada permasalahan mengenai budaya artistik media massa 
kontemporer melalui kartun, konsep sentral telah menciptakan kontur yang dapat dipahami dengan kondisi postmodern berpaling dari narasi besar yang ditemukan (Smith, 2019). Menyederhanakan secara ekstrem dan memberikan peluang lebih terhadap metanarasi kemajuan ilmiah yang tak terhindarkan telah diremehkan oleh wawasan yang dikembangkan dalam kajian kartun pada umumnya, dengan dampak mendalam pada masyarakat. Selain itu, perubahan teknologi dalam komunikasi dan media massa telah membentuk kembali cara di mana masyarakat menerima dan memahami ilmu pengetahuan seperti kemajuan yang natural (Conway, 2015). Hal tersebut dikarenakan pada kartun sarat akan makna tersembunyi, yang didominasi oleh unsur satire atau sindiran yang disampaikan secara simbolis sebagai media komunikasi baru. Satire dipilih menjadi unsur sentral karena di dalamnya memiliki aspek humor yang mampu diterima oleh berbagai macam kalangan masyarakat (Dadlez, 2011).

Penyampaian fenomena melalui humor yang bertujuan sebagai kritik atau yang sering disebut dengan humor satire (satirical humour) pernah dijelaskan oleh Ezzel dalam penelitiannya yang berjudul "Humor and Satire on Contemporary Television" (2016) dengan pendekatan analisis wacana untuk mengetahui maksud dari humor satire dalam kartun. Menurut Humor satire membutuhkan kepekaan konteks untuk mengetahui makna kritikan karena di dalamnya terdapat proses kognitif untuk memberikan sasaran yang tepat (Ezell, 2016). Di samping itu, satire merupakan gaya bahasa yang digunakan untuk menertawakan atau menolak sesuatu (Gilbert, 2015). Satire adalah gaya bahasa yang dipakai dalam kesusastraan untuk menyatakan sindiran atau ejekan terhadap suatu keadaan atau seseorang (Zoebazary, 2010). Humor satire yang tedapat dalam kartun dibuat dengan disrupsi logika berpikir (Dadlez, 2011). Ekspresi kebahasan berpola tidak sesuai dengan logika penalaranyang sesuai dengan fenomena keseharian masyarakat Indonesia. Suatu ekspresi kebahasaan tidak bisa dimaknai hanya secara tekstual, tetapi juga harus dikaitkan dengan pengalaman manusia (Lee, 2011).

Keunikan gaya penyampaian pesan persuasif melalui kartun yang menggambarkan opini dengan melebihlebihkan menjadi daya tarik untuk diteliti. Respon masyarakat yang lebih melihat kartun sebagai objek media komunikasi, hiburan, atau bahkan satire. Tentunya, indikasi keberpihakan dapat dilihat ketika masyarakat merespon tentang kartun media massa. Penelitian ini pun mencoba ikut melihat bagaimana media massa merepresentasikan fenomena kekinian dengan media kartun. Penelitian ini juga ingin menunjukkan bahwa kartun dapat menjadi salah satu cara untuk mengamati sikap masyarakat terhadap sebuah fenomena.

\section{METODE PENELITIAN}

Penerapan kualitatif digunakan dalam penelitian ini sebagai metode dalam pengumpulan data hingga analisis. Penelitian kualitatif memiliki karakteristik yaitu menekankan kondisi alamiah (natural setting) pada sasaran penelitian saat ini, memberikan perhatian utama pada makna, mengutamakan proses dibandingkan 
produk, menekankan pada deskripsi, bersifat partisipatif, dan analisisnya bersifat induktif yaitu simpulan makna dibuat berdasarkan data yang terkumpul di lapangan (Denzin \& Lincoln, 2018; Lune \& Berg, 2017; Shkedi, 2019). Teori yang digunakan adalah sudut pandang cultural studies, di mana peneliti menggunakan pendekatan interdisiplin untuk membedah permasalahan mengenai satire dan humor dalam media massa (Lune \& Berg, 2017). Diharapkan dengan menggunakan pendekatan interdisiplin, permasalahan mengenai kartun sebagai komunikasi massa, kajian satire dan humor dalam kartun, dan bagaimana respon masyarakat bisa terjawab.

Penelitian ini secara empirik dilatarbelakangi oleh pengalaman penulis selaku pengamat kartun yang menaruh minat untuk mendalami peran kartun terutama kartun dalam komunikasi massa dengan segala dinamikanya. Berdasarkan permasalahan dan proposisi dalam penelitian ini, maka kajian penelitian ini dikelompokkan sebagai berikut. Pertama, sasaran kajian terhadap perkembangan kartun dan media massa sebagai salah satu media komunikasi massa. Kedua, sasaran kajian satire dan humor yang ada dalam media komunikasi massa yang secara khusus dilihat dari sudut pandang kartun. Ketiga, sasaran kajian yang didapatkan dari respon masyarakat terhadap kartun, humor, satire, dan komunikasi massa. Ketiga fokus kajian tersebut akan menjawab permasalahan utama mengenai negosiasi yang terjadi di dalam kartun antara unsur humor, satire, dan komunikasi.

Teknik pertama pengumpulan data dalam penelitian ini adalah wawancara. Teknik ini dipakai untuk memperoleh informasi sebanyak-banyaknya dari para informan yang dipilih berdasarkan pertimbangan validitas dan otoritasnya dalam hal memberikan informasi dan akses data (Shkedi, 2019), terutama terkait dengan praktik dan kompleksitas kartun sebagai salah satu media baru dalam komunikasi massa. Dari informan ini diperoleh keterangan mengenai respon masyarakat terhadap penyampaian pesan melalui kartun di media massa yang selanjutnya dapat dipakai untuk menjelaskan pokok permasalahan penelitian ini. Teknik pengumpulan data yang kedua adalah kuesioner. Teknik ini sekalipun bukan merupakan teknik utama pengumpulan data dalam penelitian kualitatif, tetapi teknik ini digunakan sebagai pendukung, terutama untuk memperoleh data awal yang cenderung luas, namun tidak rinci dan mendalam (Kathy A. Mills, 2019; Shkedi, 2019). Kuesioner diberikan kepada 50 informan yang dipilih secara acak, agar dapat memberikan jawaban yang diperlukan sebagai bahan pendukung untuk menjelaskan pokok permasalah penelitian ini (Creswell, 2010). Kuesioner dipilih secara acak, dengan acuan untuk kuesioner pada penelitian kualitatif tidak mengikat sehingga pemilihan informan diserahkan sepenuhnya kepada peneiti sebagai instrumen utama penelitian (Kathy A. Mills, 2019; Creswell, 2010). Di dalam penelitian ini, kuesioner tidak menjadi tolok ukur utama dalam pembahasan, namun dijadikan salah satu data pendukung dalam melakukan analisa terkait respon masyarakat terhadap kartun media massa (Creswell, 2010).

HASIL DAN PEMBAHASAN

Disrupsi Budaya Komunikasi dalam Kartun dan Media Massa 
Budaya adalah fenomena yang diproduksi secara intersubjektif yang dimiliki publik memberikan keleluasaan sarana pertukaran sosial, dan rasa kebersamaan (Malinowski, 1944). Di dalam perjalanan era revolusi industri 4.0 dan era internet of thing (IoT), budaya publik tentang demokrasi sosial semakin menjadi dikomersialkan dan dipasarkan berkenaan dengan era disrupsi yang justru membuatnya menjadi estetika baru. Hal tersebut juga ditandai dengan munculnya budaya global yang terfragmentasi yang dibangun di atas kesenangan yang lebih populer. Budaya transnasional ini membangun identitas baru dan merusak solidaritas nasional versi lama yang biasanya digagas melalui media (Grossman, 2017; Kathy Ann Mills, 2016). Gagasan kritis tentang ruang publik membantu kita melihat proses ini secara ambivalen. Perkembangan teknologi dan bentuk budaya baru tampaknya tergantung pada cara konsumsi yang diprivatisasi alihalih prinsip-prinsip debat dan diskusi terbuka. Jika dilihat dengan sudut pandang cultural studies, maka terdapat dominasi kelas yang mengatur pertukaran budaya. Era 'kesopanan' bermedia sudah dianggap usang sehingga publik lebih menyukai halhal kontradiktif juga kontroversial sebagai santapan bermedia dan berkomunikasi di era saat ini (Klein, 2013; Lloro-Bidart, 2015). Komunikasi massa yang 'sopan' sejauh ini tidak menarik perhatian yang semestinya (Remley, 2017). Era disrupsi menyebabkan komunikasi penuh humor di karya seni ruang publik sering mengisolasi kekhawatiran dari perkembangan intelektualnya di kemudian hari dan membuat kontribusinya lebih fokus pada media komunikasi satire daripada pesan komunikasinya (Davis, 2017; Melton,
2018; Samuk, 2015; Weisgerber, 2019). Organisasi sistemik budaya media dapat dirumuskan ulang sejalan dengan keanekaragaman budaya yang dimiliki dan memaksakan kewajiban yang wajar kepada mereka yang ingin terlibat dalam dialog budaya atau politik komunikasi yang sarat humor dan satire (Hardy, 2017; Stokes, 2016). Memang, dalam hal ini berawal dari kegagalan kapitalisme liberal dan runtuhnya sosialisme ilmiah menandakan peluang baru untuk cara atau metode baru dalam komunikasi massa.

Kartun telah bertahun-tahun menjadi fitur utama konten surat kabar, majalah, dan media massa lainnya (Etty, 2019). Pengamatan panorama akan mengungkapkan bahwa sebagian besar media massa menerbitkan berbagai kartun dan komik. Di luar negeri ada Punch, The Guardian, New Nigerian, Tell, Newswatch, the News, yang konsisten menjadikan konten fitur sebagai media utama yang menyiratkan isi bahasan saat itu sepertihalnya Kompas, Jawa Pos, dan Kedaulatan Rakyat di Indonesia. Semuanya menerbitkan kartun dan komik tentang urusan sosial, politik dan ekonomi negara atau sebagai ilustrasi dari beberapa masalah editorial. Kartun pada awalnya dianggap sebagai sarana pelarian untuk menyepelekan isu-isu politik dan sosial yang sangat serius dari kehidupan manusia. Tetapi yang terjadi justru sebaliknya. Kartun memunculkan kontradiksi sosial dalam masyarakat dengan cara yang luhur, di mana mereka juga menyediakan sarana untuk mendidik pembaca dan sama-sama menawarkan otonomi atas interpretasi dari opini yang disampaikan dalam kartun (Lewis \& Lewis, 2018; Schama, 2012; Smith, 2019). 
Beberapa kartun di media massa telah memiliki popularitas sehingga beberapa surat kabar dan majalah dicari oleh beberapa pembaca karena kartun mereka. Di dalam komunikasi massa, aliran pemikiran tertentu berpendapat bahwa media massa mempromosikan kepentingan budaya, ekonomi, dan politik dari kelas dominan di masyarakat (Facca \& Aldrich, 2011; Fott, 2009; Graham, 1997; Selwyn, Boraschi, \& Özkula, 2009; Uidhir, 2013), yang berkaitan dengan pandangan para cendekiawan seperti Theodore Adorno, Max Horkheimer dan Herbert Marcuse (The Frankfurt School) dan para cendekiawan Marxis lainnya seperti Stuart Hall dan John Fiske (Ida, 2014; Storey, 2006). Pandangan mereka didasarkan pada gagasan Marx dan Engels yang menyatakan bahwa ide-ide kelas penguasa ada di setiap zaman, ide-ide yang berkuasa yaitu kelas yang merupakan kekuatan material masyarakat yang berkuasa sekaligus kekuatan intelektual dari yang berkuasa (Uidhir, 2013). Kelas yang memiliki sarana produksi materi yang tersedia memiliki kontrol pada saat yang sama atas sarana produksi mental, sehingga dengan demikian secara umum, ide-ide mereka yang tidak memiliki sarana produksi mental tunduk padanya, dan kartun merupakan media yang 'halus' karena komunikasi terjadi pada interpretasi atas simbol-simbolnya (Bourdieu, 1999; Werner \& Kaplan, 1963). Namun, tidak semua aspek media massa berfungsi dengan cara yang sama atau sesuai dengan paradigma Marxis, di mana kartun media massa pada umumnya membangkitkan humor dan tawa dari pembaca dapat diartikan sebagai upaya oleh editor surat kabar untuk meremehkan masalah serius dan dengan implikasi mendamaikan perseteruan atau fenomena genting yang sedang terjadi (Gomez-palacio \& Vit, 2009; Hall, 2002; Malinowski, 1944; Mészáros, 2006).

Berkaitan dengan kartun yang memiliki urgensi dalam penyebaran budaya, ideologi, identitas dan juga pesan, unsur visual sangat membantu dalam membangkitkan minat pembaca (Kress \& Leeuwen, 2012). Di media cetak, kartun sama-sama membantu memberikan gambaran mental yang jelas, mempercepat pemahaman, membantu memori dan memberikan pengalaman bersama. Beberapa kartun bahkan ditampilkan tanpa teks atau penjelasan tertulis, namun pesan yang melekat di dalamnya masih dipahami oleh pembaca.

Gambar atau ilustrasi grafik dan komentar dalam kartun tentang isu-isu politik dan sosial tidak hanya dimaksudkan untuk menciptakan kesenangan bagi para pembaca tetapi mereka juga berusaha untuk memperdalam daya pemikiran kritis para pembacanya (Darbellay \& Moody, 2017). Kartun politik seringkali menyindir dan menghukum kejahatan sosial, sudut pandang atau ideologi, atau peristiwa yang berkaitan dengan penguasa (Ferriss-Hill, 2019; Gilbert, 2015). Karenanya, kartun adalah alat vital yang digunakan oleh pers untuk peran pengawasnya di masyarakat. Kartun menawarkan 'kemunduran dari kenyataan' dan kondisi nyata di mana dalam banyak hal di dunia ini tidak bisa dianggap nyaman (Chandler, 2017). Meskipun banyak kartun yang sepenuhnya serius dalam niat awal penyampaiannya, namun tetap tidak bisa mengesampingkan apalagi menghilangkan kesan humor yang ada di dalamnya. Kartun bisa dilihat sebagai arena latihan terhadap kepekaan masalah dan solusi atas fenomena genting 
yang sedang hangat diperbincangkan dengan kartunis bertindak sebagai mediator hati nurani atau suara rakyat (Coebel, 2009; Hardy, 2017; Melton, 2018). Lebih lanjut, kartunis berfungsi sebagai pencatat peristiwa, yang disajikan secara grafis (Schlund-Vials, 2011). Membaca kartun dari periode tertentu pasti akan membantu dalam mengingat peristiwa besar yang terjadi pada periode itu. Fitur umum dari kartun adalah pemahaman yang baik tentang fenomena saat ini yang dengan jelas mengidentifikasi masalah politik yang bersifat lokal dan internasional yang disampaikan atas keterampilan tangan dan pembahasaan secara visual (Gomez-palacio \& Vit, 2009; Weisl-Shaw, 2010).

\section{Humor dan Satire dalam Kartun}

Sepanjang sejarah, kartun-kartun yang ada di media massa telah memainkan peran penting dengan merangkum sebuah situasi kompleks dalam satu gambar yang menjelaskan segalanya. Dengan demikian, kartun yang dianggap sederhana ini membawa perubahan dan pemahaman sekaligus. Penyisipan unsur humor dalam kartun merupakan gerakan penting dalam kampanye kartun sebagai salah satu bentuk media konstruksi sudut pandang masyarakat (Lloro-Bidart, 2015).

Humor dalam kartun mudah diterima karena telah menyebar luas di zaman postmodern saat ini; dengan kata lain, hampir semuanya dapat dihumorkan dan diparodikan (Mack, 2007). Satire adalah kategori humor berdasarkan intertekstualitas. Oleh karena itu, satire dibangun berdasarkan pengucapan hal-hal yang bersifat umum yang bertentangan dengan ekspresi humor lain yang dibangun menggunakan prosedur visual (Martin,
2012; Martin \& Ford, 2018). Dalam triadik humor, satire, dan parodial, terjadi interelasi tiga unsur yang hidup berdampingan. Fenomena sebagai teks orisinal adalah rujukan; teks parodik menemukan fondasinya di ejekan berdasarkan aslinya; sedangkan visualisasi yang berujud kartun merangkum kesemuanya (Liu \& Luton, 2011; Mack, 2007). Sindiran didefinisikan sebagai praktik diskursif yang sering diintegrasikan ke dalam praktik humor sehari-hari yang membuat pembacanya memiliki sudut pandang yang berbeda dengan memerhatikan elemen (1) kartunis, (2) satiree, yaitu penerima dalam hal ini adalah pembaca, dan (3) target kritik (Dadlez, 2011; Melton, 2018).

Berkenaan dengan sifat-sifat pewacanaan visualnya, kartun dianggap sebagai wacana tingkat tinggi, karena dapat menggunakan genre primer yang membangun hubungan dialektis (Rossing, 2019). Dengan cara ini, kartun mengaktifkan peristiwa diskursif nyata yang sebelumnya hanya menjadi wacana. Disonansi antara domain asli dan domain dialektislah yang menciptakan kerangka pragmatis untuk penafsiran dalam kartun (Dadlez, 2011). Humor memberikan peluang menginterpretasi dan merespon secara kritis terhadap wacana serius (Hardy, 2017).

Humor dalam kartun dikonstruksi berdasarkan konten yang sama sekali berbeda terkait dengan berita terkini di media, yang mengubahnya menjadi sejenis wacana yang tidak secara eksklusif mencari tawa sebagai tanggapan oleh pemirsa, tetapi efek yang lebih dalam yang mencoba memicu refleksif reaksi yang membuat penonton mengadopsi sikap kritis dan mengevaluasi topik yang 
menjadi objek humor (Dentith, 2002; Hardy, 2017; Hutcheon, 2000; Liu \& Luton, 2011; Mack, 2007).

Kesimpulannya, humor dan satire dalam kartu dapat dikatakan mewakili praktik diskursif lucu yang dekat dengan sindiran yang telah menjadi lahan diskursif dalam media massa. Dengan asumsi bahwa humor dan satire dalam kartun merupakan bentuk pewacanaan dan bahkan pendidikan bagi masyarakat, terdapat empat fitur penting yang mengidentifikasinya (Daddesio, 2013; Dadlez, 2011; Dentith, 2002; Hardy, 2017; Hutcheon, 2000; Liu \& Luton, 2011; Mack, 2007):

1. Representasi yang disengaja dari objek yang diparodikan, yang meliputi bentuk aktualisasi yang sarat satire atas peristiwa, tindakan, kepercayaan dan pemikiran.

2. Memamerkan representasi yang mencoba untuk mengingatkan atau membawa tindakan atau peristiwa sebelumnya yang diparodikan ke memori pembaca.

3. Tindakan kritis, yang mengolok-olok objek realitas menjadi humor dan parodi.

4. Tindakan komik sebagai tindakan esensial terakhir dari parodi atas fenomena. Hal tersebut dilakukan untuk mencapai 'kesenangan' atau humor. Kartunis memberikan batasan-batasan yang digunakan untuk menghasilkan representasi yang disengaja dari objek parodi, memamerkan representasi dan membatasi kritik; singkatnya, ia mengintegrasikan atau memanipulasi ketiga jenis aksi ini dengan tujuan menciptakan komik tersebut.

Oleh karena itu, komunikasi massa melalui kartun didasarkan pada intertekstualitas atau dengan kata lain parodi secara dialektik menentang teks asli dengan teks visual yang dibangun sebagai parodi (Hutcheon, 2000; Mack, 2007; Young, 2017). Kartun memiliki komponen ideologis dan dapat menyiratkan penggunaan informasi yang sembrono (Etty, 2019).

Kartunis cenderung menampilkan fenomena secara satire dan humor, pejabat dan kelas atas masyarakat sebagai subyek cemoohannya (Rowden, 2013). Kartunis dan perdagangannya dapat disamakan dengan satiris tradisional atau pelawak pengadilan di istana (Hawkesworth, Cawood, Kemp, Storey, \& Dhuime, 2009; Somekh, 2006). Dia bebas memuji penguasa, membuatnya marah tanpa menghadapi hukuman apa pun. Dalam masyarakat tradisional, satiris berfungsi sebagai lembaga kontrol sosial (Samuk, 2015). Fungsi tersebut bisa terepresentasikan dalam bentuk lagu, puisi di segala posisi masyarakat berada di dalam fenomena yang direpresentasikan. Peran ini tidak hanya dimainkan oleh satiris saja, tetapi juga oleh seniman lain seperti pelukis, musisi, dan performer artist. Semua ini direplikasi dalam kartun karena generasi saat ini lebih maju dalam literasi dibandingkan dengan masyarakat tradisional pada zaman dahulu (Dobinson \& Dunworth, 2019; Gilster, 1997; Hicks \& Turner, 2013).

Kartun menawarkan hiburan bagi pembaca media massa di mana hiburan adalah salah satu peran utama pers di masyarakat (Rowden, 2013). Dengan karya seninya, kartunis menghibur orang ketika mereka berada dalam kondisi psikologis yang kurang baik. Seperti yang diutarakan oleh Jonathan Rossing bahwa 
kartun cenderung mengandalkan dampaknya pada spontanitas, kegembiraan, citra populer, dan kerap menampilkan humor yang vulgar sehingga seakan kartun memberikan metode yang tepat untuk mengolok-olok sesama, lembaga, dan diri sendiri (Davis, 2017; Ezell, 2016; Melton, 2018; Weisgerber, 2019).

\section{Perspektif Masyarakat terhadap Kartun}

Kartun sebagai media komunikasi massa telah diterima oleh masyarakat. Hal tersebut disebabkan di era saat ini mode penyampaian konvensional mulai ditinggalkan (Young, 2017). Masyarakat lebih cenderung menyukai penyampaian pesan secara santai dengan sisipan humorhumor. Satire dalam kartun sebagai komunikasi massa di Asia Tenggara biasanya disampaikan dengan memberikan unsur humor terhadap fenomena yang sebelumnya bukan menjadi arenanya. Salah satunya Kartun Clekit yang dibuat oleh Wahyu Kokkang di Surat Kabar Jawa Pos yang menanggapi berbagai peristiwa melalui kartun opini. Kartun opini sangat penting hadir di halaman media massa sebagai bentuk penyampaian fenomena terkini dalam bentuk visual (Gomezpalacio \& Vit, 2009; Kathy Ann Mills, 2016). Pesan kartun opini selevel keseriusannya dengan pesan-pesan yang tersampaikan lewat artikel berita, akan tetapi secara pesan visual, kartun lebih mudah dicerna dan dipahami dikarenakan sifatnya lebih ringan dan tidak bertele-tele (Konstantakos, 2015; Kress \& Leeuwen, 2012; McAleer, 2010).
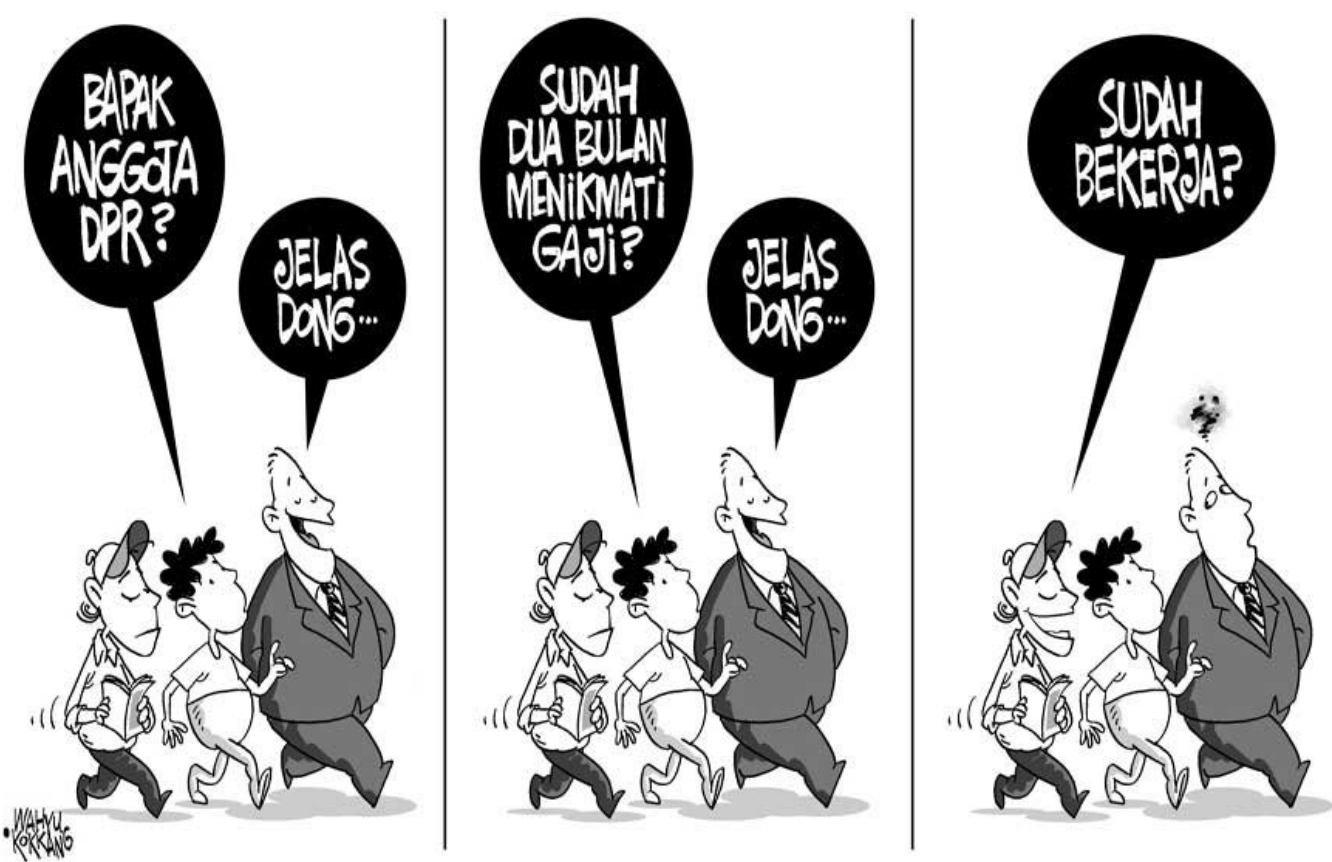

Sumber: https://twitter.com/jawapos/status/538578099118436353

Gambar 1. Kartun Clekit: “Gaji Sudah, Kerja Belum” karya Wahyu Kokkang

Kartun Clekit mempermudah pembaca mengingat sebuah peristiwa dibandingkan proses harus membaca berita dalam bentuk tulisan yang biasanya membutuhkan durasi lebih lama didalam mencerna berita. Kartun Clekit memvisualisasikan karakter tokoh yang tidak seperti bentuk objek orisinilnya, namun simbol dalam desainnya menekankan pada pemaknaan gambar 
kartun (Daddesio, 2013). Simbol diamati dari pemilihan bahasa verbal, desain grafis, atau point of interest gambar. Keseluruhannya menggunakan representasi tertentu mengenai peristiwa yang terjadi sehingga menjadikannya sebagai salah satu bentuk media komunikasi masyarakat. Oleh karenanya, fungsi Kartun Clekit sebagai opini berbentuk visual adalah mengingatkan khalayak masyarakat dan pemerintah bahwa di sekitar mereka terdapat fenomena yang layak dikritisi. Tujuan Wahyu Kokkang dalam kritik lewat Kartun Clekit adalah menyuarakan fenomena secara simbolis atas hal-hal yang terjadi di masyarakat. Serupa namun tak sama, terdapat satu portal berita yang memanfaatkan teknologi Automated Insight (AI) sebagai penyebar informasinya yaitu Beritagar.id, sebuah situs kurasi berita dari berbagai jenis media daring. Di dalamnya terdapat beberapa fitur media yaitu kartun sebagai representasi simbolik atas fenomena yang terjadi.

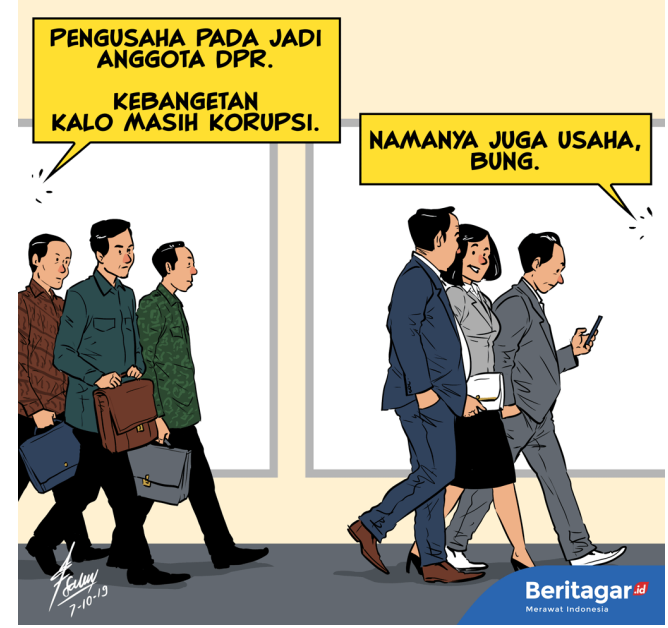

Sumber: beritagar.id, 2019

Gambar 2. Tampilan kartun editorial di beritagar.id

Respon masyarakat terhadap dua sampel kartun media massa cenderung mengarah ke kemampuan persuasif kartun dalam mengonstruksi pemikiran masyarakat. Sesuai dengan survey yang dilakukan terhadap 50 responden yang ditentukan secara acak, 64\% mengaku sering menikmati kartun yang ada di media massa. Mereka menyisihkan waktu untuk sekadar melihat secara detail sebelum mengkaji dan membicarakannya. Di sisi lain, rasio tersebut harus diapresiasi karena dapat menjadi acuan awal tingkat literasi masyarakat yang cenderung baik.

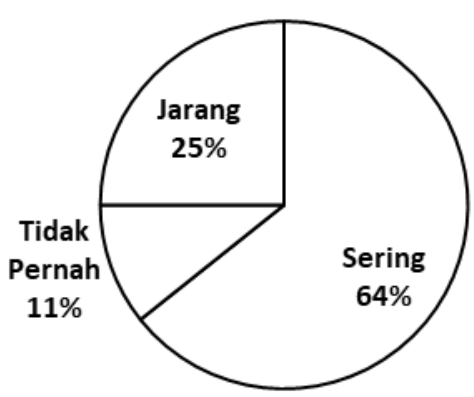

Sumber: Data kuesioner penulis, 2019

Gambar 3. Presentase Penikmat Kartun Media Massa

"Banyak kritik pemerintah menggunakan area abu-abu interpretasi sebagai perlindungan terhadap kaum elit", ujar Siti yang merupakan mahasiswa Ilmu Komputer.

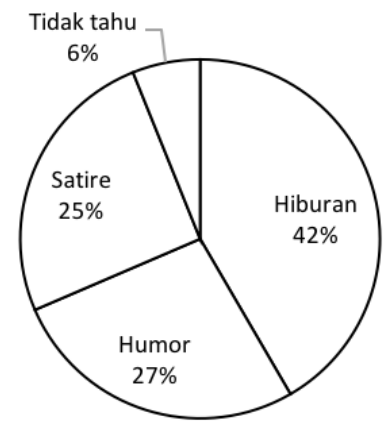

Sumber: Data kuesioner oleh penulis, 2019

Gambar 4. Presentase sudut pandang masyarakat terhadap kartun media massa

Kartun politik juga merupakan arena artistik yang bercirikan bahasa metaforis dan satire. Hal ini menunjukkan adanya konteks, masalah, dan perbedaan 
situasi politik di setiap penyampaiannya (Pace, 2018).

"Satire secara tradisional telah digunakan sebagai senjata oleh yang kaum subordinan melawan para dominan." ujar Rahmad yang merupakan mahasiswa Ilmu Komunikasi.

Selama proses memberikan opini ke dalam bentuk visual melalui kartun, banyak kreasi artistik mengenai simbol, teknik, dan komposisi yang harus dibuat (Painter, Martin, \& Usworth, 2012). Ketika proses pembuatan, kartunis juga melakukan analisis peluang terhadap tingkat penerimaan masyarakat. Ketika masyarakat mampu memahami maknanya, kartun dapat memenuhi fungsi penting dalam mengkritik dan mengendalikan dalam masyarakat (Samuk, 2015; Weisgerber, 2019). Selain itu, kartun politik dapat mendorong proses pembentukan opini dan pengambilan keputusan serta memberikan perspektif yang menghibur pada berita yang terkesan konvensional bagi beberapa kalangan.

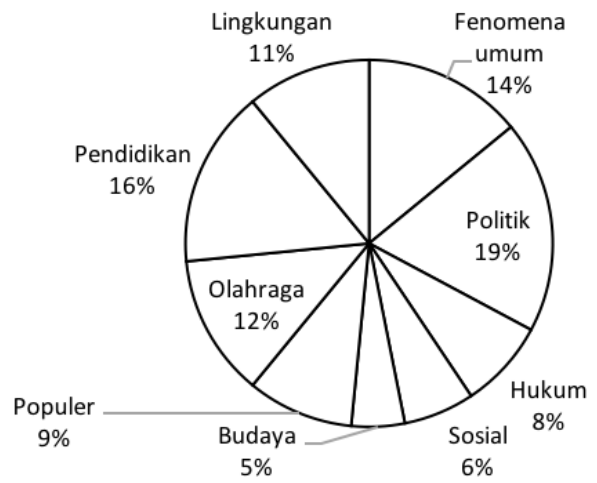

Sumber: Data kuesioner oleh penulis, 2019

Gambar 5. Presentase bidang topik kartun media massa menurut masyarakat

Bidang politik menjadi salah satu disiplin yang menjadi 'prioritas' untuk diolah menjadi kartun. Hal tersebut berkaitan dengan arena bermain bidang politik yang sarat akan posisi-posisi tinggi, yang sedikit menutup peluang masyarakat masuk ke dalamnya. Hal tersebut membuat kartun menjadi lahan yang dengan nyaman dimasuki para pengkritik untuk mengaktualisasikan kegelishannya dalam bentuk visual.

"Saya suka bahasan tentang politik, keamanan, dan korupsi, yang semuanya berbahaya sampai batas tertentu.", ujar Bayu yang merupakan mahasiswa Kajian Budaya.

Sepanjang sejarah, kartun politik telah memainkan peran penting dalam pembentukan konstruksi selera masyarakat. Dengan beberapa goresan artistik melalui simbolisasinya, kartun mampu merangkum sebuah situasi kompleks dalam satu gambar yang menjelaskan fenomena hangat yang sedang terjadi. Dengan demikian, kartun yang sederhana ini membawa perubahan.

"Segalanya menjadi lebih mudah karena kartun satire seperti ini memberi masyarakat banyak hal untuk dibicarakan... dan sebenarnya jika dimaknai secara mendalam, sindirannya lebih keras, namun semakin keras maka semakin menarik perhatian publik luas.", ujar Han, mahasiswa Ilmu Kedokteran.

Kartun dalam media sosial memiliki elemen positif dan negatif untuk memadukan antara humor dan satire. Media sosial mampu menciptakan efek push-and-pull dalam hubungan penuh antara satiris politik, masyarakat dan pemerintah. 


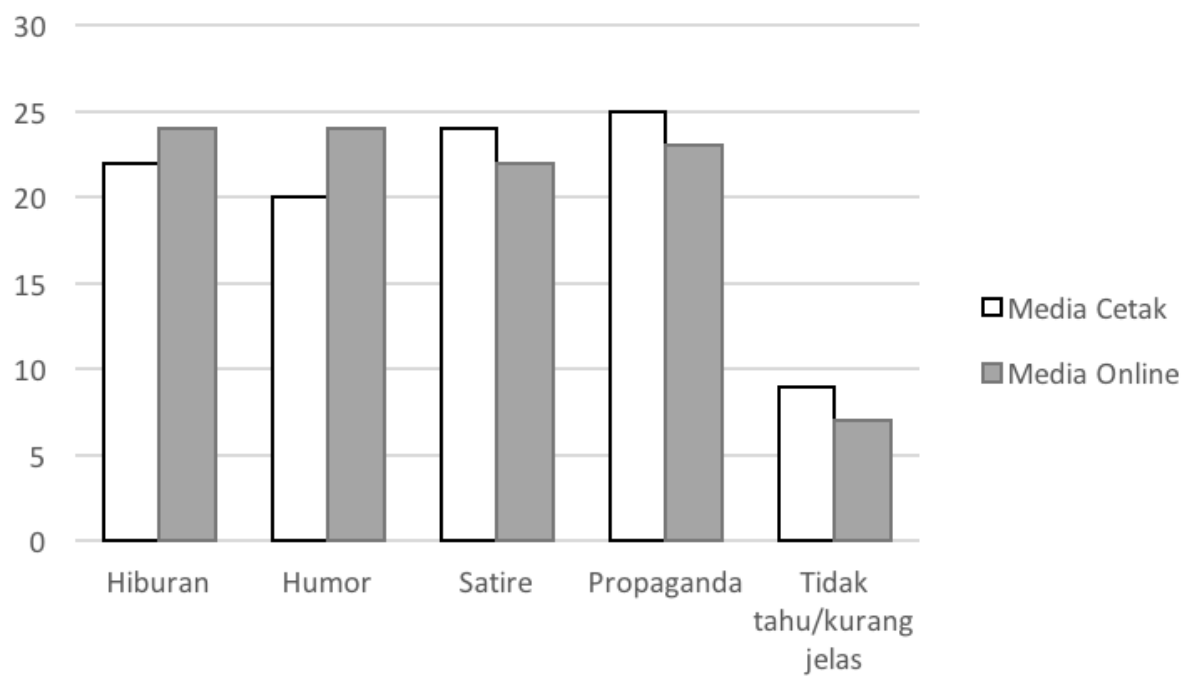

Sumber: Data kuesioner oleh penulis, 2019

\section{Gambar 6. Perbandingan keterbacaan kartun di media massa offline dan online}

Masyarakat menganggap

keterbacaan makna dari kartun media massa sudah cukup jelas. Perbandingan cukup terlihat dalam sudut pandang masyarakat terhadap genre spesialisasi dalam media massa. Kartun yang ditampilkan dalam media cetak lebih cenderung dikonstruksi sebagai pewacanaan atas propaganda. Dengan sedikit yang menganggap kartun media cetak sebagai media hiburan dan humor, maka masyarakat Indonesia masih belum mampu beranjak dari ranah kosntruksi identitas yang bersifat fiskal. Berbeda dengan bagaimana masyarakat melihat kartun di media online, yang lebih menganggapnya sebagai media hiburan semata.

\section{SIMPULAN}

Kartun dengan humor dan satire di era disruptif menjadi salah satu media yang efektif untuk mengomunikasikan masalah-masalah penting. Kombinasi triadiknya memiliki kemampuan mewujudkan dan mentransfer isyarat atau pesan atas fenomena yang terjadi dengan cara yang unik dan memberikan persepsi subliminal. Ketika masyarakat terusmenerus terpapar gambar tertentu, mereka menjadi lebih setuju dengan gambar yang diproyeksikan dengan lebih dahulu melakukan kajian sederhana atas gambar yang dilihatnya. Humor dan satire yang tersampaikan melalui kartun media massa cenderung efektif karena dapat menghancurkan penghalang rasa takut untuk beropini, terutama jika menyangkut persoalan politik tingkat atas. Kartun dapat menggerakkan dan memobilisasi masyarakat untuk melihat ke arah yang diinginkan oleh kartunis. Oleh karenanya, tingkat intelektualitas kartunis sangat berpengaruh. Kartun tidak hanya dimaksudkan sebagai humor, tetapi juga alat yang ampuh untuk mendorong perubahan. Humor dan satire dalam kartu dapat dikatakan mewakili praktik diskursif lucu yang dekat dengan sindiran yang telah menjadi lahan diskursif dalam media massa. Dengan asumsi bahwa humor dan satire dalam kartun merupakan bentuk pewacanaan dan bahkan pendidikan bagi masyarakat. 


\section{DAFTAR PUSTAKA}

Adesope, O. O., \& Rud, A. G. (2019). Contemporary Technologies in Education: Maximizing Student Engagement, Motivation, and Learning. Singapore: Springer International Publishing.

Bourdieu, P. (1999). Language and Symbolic Power. United Kingdom: Harvard University Press.

Chandler, D. (2017). Semiotics: The Basic (3rd Editio). London: Routledge.

Coebel, B. A. (2009). Comic Relief: Engaging Students through Humor Writing. The English Journal, 98(6), 38-43.

Conway, P. (2015). Preservation in the Age of Google : Digitization, Digital Preservation, and Dilemmas. The Library Quarterly: Information, Community, Policy, 80(1), 61-79.

Creswell, J. W. (2010). Research Design Pendekatan Kualitatif, Kuantitatif, Dan Mixed. Yogyakarta: Pustaka Pelajar.

D'Angelo, F. J. (2010). The Rhetoric of Intertextuality. Rhetoric Review, 29(1), 31-47.

Daddesio, T. C. (2013). On Minds and Symbols: The Relevance of Cognitive Science for Semiotics. Berlin: Mouton de

Gruyter. http://doi.org/10.1515/978311090300 3

Dadlez, E. M. (2011). Truly Funny: Humor, Irony, and Satire as Moral Criticism. The Journal of Aesthetic Education, 45(Spring), 1-17. http://doi.org/10.5406/jaesteduc.45.1. 0001

Darbellay, F., \& Moody, Z. (2017). Creativity Design Thinking and Interdisiplinarity. Singapore: Springer Nature.

Davis, J. M. (Ed.). (2017). Satire and Politics: The Interplay of Heritage and Practice (Palgrave S). New York: Palgrave Macmillan.

Dentith, S. (2002). Parody: The New Critical Idiom (The New $\mathrm{Cr}$ ).
London: Routledge.

Denzin, N. K., \& Lincoln, Y. S. (Eds.). (2018). The SAGE Handbook of Qualitative Research (Fifth Edit). Los Angeles: Sage Publications. http://doi.org/10.1007/s11229-0171319-x

Dobinson, T., \& Dunworth, K. (2019). Literacy Unbound: Multiliterate, Multilingual, Multimodal. Singapore: Springer International Publishing.

Etty, J. (2019). Graphic Satire in the Soviet Union: Krokodil's Political Cartoons. Mississippi: The University Press of Mississippi. http://doi.org/10.1017/CBO97811074 15324.004

Ezell, S. K. (2016). Humor and Satire on Contemporary Television: Animation and the American Joke (The Cultur). New York: Routledge.

Facca, A. E., \& Aldrich, J. W. (2011). Putting the Past to Work for the Future. The Public Historian, 33(3), 38-57.

http://doi.org/10.1525/tph.2011.33.3. 38

Ferriss-Hill, J. L. (2019). Roman Satire and the Old Comic Tradition. New York: Cambridge University Press. http://doi.org/10.1017/CBO97811074 15324.004

Fott, D. (2009). John Dewey and the Mutual Influence of Democracy and Education. The Review of Politics, 71(Political Philosophy in the Twentieth Century), 7-19.

Gilbert, C. J. (2015). If This Statue Could Talk: Statuary Satire in the Pasquinade Tradition. Rhetoric and Public Affairs, 18(Spring), 79-112. http://doi.org/10.14321/rhetpublaffa.1 8.1.0079

Gilster. (1997). Digital Literacy. New York: Wiley.

Gomez-palacio, B., \& Vit, A. (2009). Graphic Design Referenced: A Visual Guide to the Language, Applications, and History of Graphic Design. Massachusetts: Rockport Publishers, Inc. 
Gopnik, A. (2019). High and Low: Caricature, Primitivism, and the Cubist Potrait. Art Journal, 43(4), 371-376.

Graham, G. (1997). Philosophy of the Art. London: Routledge.

Grossman, J. (2017). Adaptation in Visual Culture. Adaptation in Visual Culture. New York: Palgrave Macmillan.

http://doi.org/10.1007/978-3-31958580-2

Hall, S. (2002). Representations: Cultural Representations and Signifying Practices. London: Sage Publications.

Hardy, D. (2017). Humour in the Visual Arts and Visual Culture: Practices, Theories, and Histories. RACAR: Revue d'art Canadienne, 37(1), 1-9.

Hawkesworth, C. J., Cawood, P. A., Kemp, A. I. S., Storey, C. D., \& Dhuime, B. (2009). A Matter of Preservation. Science, 323(5910), 4950.

http://doi.org/10.1126/science.116854 9

Haywood, I. (2019). Romanticism and Caricature. United Kingdom: Cambridge University Press. http://doi.org/10.1017/CBO97811074 15324.004

Hicks, T., \& Turner, K. H. (2013). No Longer a Luxury: Digital Literacy Can't Wait. The English Journal, 102(6), 58-65. http://doi.org/10.4135/978141295740 $3 . n 296$

Hutcheon, L. (2000). A Theory of Parody: The Teachings of Twentieth-Century Art Forms. Los Angeles: University of Illinois Press.

Ida, R. (2014). Studi Media dan Kajian Budaya. Jakarta: Prenada Media Group.

Klein, S. R. (2013). Humor in a Disruptive Pedagogy Further Considerations for Art Educators. Art Education, 66(6), 34-39.

Konstantakos, I. M. (2015). Machon's Alexandrian Comedy and Earlier Comic Tradition. Aevum, Anno 89(1),

$$
13-36 .
$$

Kress, G., \& Leeuwen, T. van. (2012). Reading Images: The Grammar of Visual Design. London: Routledge.

Lee, D. (2011). Cognitive Linguistics: An Introduction. United Kingdom: Oxford University Press.

Lewis, R. L., \& Lewis, S. I. (2018). The Power of Art. New Jersey: Cengage Learning.

Liu, C. H., \& Luton, F. (2011). Vygotsky's Psycho-semiotics: Theories, Instrument and Interpretive Analyses. Berlin: Peter Lang.

Lloro-Bidart, T. (2015). A Political Ecology of Education in/for the Anthropocene. Environment and Society, 6, 128-148.

Lune, H., \& Berg, B. L. (2017). Qualitative Research Methods for the Social Sciences (Ninth edit). Essex: Pearson.

Mack, R. L. (2007). The Genius of Parody: Imitation and Originality in Seventeenth and Eighteenth Century English Literature. United Kingdom: Palgrave Macmillan.

Malinowski. (1944). A Scientific Theory of Culture and Other Essays. New York: Oxford University Press.

Martin, R. A. (2012). Psychology of Humor: An Integrative Approach. London: Academic Press.

Martin, R. A., \& Ford, T. E. (2018). The Psychology of Humor: An Integrative Approach (Second edi). London: Academic Press.

McAleer, P. R. (2010). El Proceso, Kafka, and the Comic Novel: Ana Maria Shua's Soy Paciente and the Fear of Individual Freedom. The Modern Language Review, 105(1), 131-148.

Melton, J. (2018). When the Candle Goes Out: The Complexity of Simple Jokes and the Limits of Satire. Studies in American Humor, 4(2), 152-159. http://doi.org/10.5325/studamerhumo r.4.2.0152

Mészáros, I. (2006). Marx's Theory of Alienation (Fifth edit). New Jersey: Merlin Press. 
Mills, K. A. (2016). A Review of the " Digital Turn " in the New Literacy Studies. Review of Educational Research, 80(2), 246-271.

Mills, K. A. (2019). Big Data for Qualitative Research. Routledge Focus. Oxon: Routledge. http://doi.org/10.4324/978042905641 3

Pace, M. (2018). Subliminal Psychology 101: How to Stealthily Penetrate, Influence, and Subdue Anyone's Mind Without Them Suspecting a Thing. Canada: Createspace Independent Publishing Platform.

Painter, C., Martin, J. R., \& Usworth, L. (2012). Reading Visual Narratives. United Kingdom: MPG Group Books.

Remley, D. (2017). The Neuroscience of Multimodal Persuasive Messages: Persuading the Brain. New York: Routledge. http://doi.org/10.4324/978131520632 5

Rossing, J. P. (2019). An Ethics of Complicit Criticism for Postmodern Satire. Studies in American Humor, 5(Special Issue: Satire Today), 1330.

http://doi.org/10.5325/studamerhumo r.5.1.0013

Rowden, C. (2013). Memorialisation, Commemoration and Commodification: Massenet and Caricature. Cambridge Opera Journal, 25(2), 139-163.

Samuk, T. (2015). Satire and the Aesthetic in As You Like It. Renaissance Drama, 43(2), 117-142. http://doi.org/10.1086/683106

Schama, S. (2012). The Power of Art. London: The Bodley Head Ltd.

Schlund-Vials, C. J. (2011). Crisis of Memory: Memorializing 9/11 in the Comic Book Universe. Modern Language Studies, 41(1), 12-25.

Schultz, D. (2016). Public Affairs Education for a New Generation. Journal of Public Affairs Education, 22(1), 7-10.
Selwyn, N., Boraschi, D., \& Özkula, S. M. (2009). Drawing Digital Pictures: An Investigation of Primary Pupils' Representations of ICT and Schools. British Educational Research Journal, 35(6), 909-928. http://doi.org/10.1080/014119209028 34282

Shkedi, A. (2019). Introduction to Data Analysis in Qualitative Research. Singapore: Springer International Publishing.

Smith, K. S. (2019). Architectural Sketches and the Power of Caricature. Journal of Architectural Education, 44(1), 49-58.

Somekh, B. (2006). Action Research: a Methodology for Change and Development. Berkshire: Open University Press.

Stokes, J. (2016). Competencies: A Unifying Thread for Education, Practice and Public Protection. Canadian Social Work Review / Revue Canadienne de Service Social, 33(1), 125-132.

Storey, J. (2006). Cultural Studies dan Kajian Budaya Pop. Yogyakarta: Jalasutra.

Uidhir, C. M. (2013). Epistemic Misuse and Abuse of Pictorial Caricature. American Philosophical Quarterly, 50(2), 137-151.

Weisgerber, J. (2019). Satire and Irony as Means of Communication. Comparative Literature Studies, 10(2), 157-172.

Weisl-Shaw, A. (2010). The Comedy of Didacticism and the Didacticism of Comedy in Calila E Dimna and Sendebar. The Modern Language Review, 105(3), 732-742.

Werner, H., \& Kaplan, B. (1963). Symbol Formation: An OrganismicDevelopmental Approach to Language and the Expression ff Thought. New York: Wiley.

Young, R. O. (2017). Persuasive Communication: How Audiences Decide (2nd editio). New York: Routledge. 
http://doi.org/10.4324/978131568711 7

Zoebazary, I. (2010). Kamus Istilah

Televisi dan Film. Jakarta: Gramedia Pustaka Utama. 